\title{
Entrepreneurial innovative network and the design of socio-economic neural system
}

\author{
Olga Tikhomirova, National Research University ITMO, Saint Petersburg, Russia \\ https://orcid.org/0000-0003-2288-2588
}

\begin{abstract}
This article aims to establish how an idea becomes an innovation and how creativity, collective dynamics, and information are interconnected. The results of the study showed that the emergence of innovations is closely connected with collective collaboration, and that it is impossible outside of group dynamics. The process of self-organization and collective decision-making is realized through a synergistic interaction, which then transforms into the so-called "information laser" and serves as a basis for the emergence of innovation. Both individuals (as persons and as separate entrepreneurs) are the elements of the innovation system and the actors of the artificial neural network-socioeconomic neural systems (SENS-systems). These systems act through self-organization and corporate collaboration, and the efforts of each element are amplified through the interaction with the other elements. The model of the SENS-systems can explain how the individual idea transforms into innovation and spreads throughout the world.
\end{abstract}

\section{KEYWORDS}

Collective Decision-Making, Corporate Collaboration, Creativity, Information Laser, Innovation Network, Innovation, Neural Network, Self-Organization

\section{INTRODUCTION}

As a rule, innovation is considered as a process of creation of new technics and/or technologies. A common understanding often equates innovation and invention, and innovation and creativity. In the $19^{\text {th }}$ century, separate inventors, engineers, and business leaders created unique ideas, machines, technologies, and businesses. In the current global world, all companies and businesses are interdependent, thus they have to interact and cooperate to get their own goals.

Now is the time to discuss how separate innovators, organizations, and different distributed settings become a driver of creativity and innovation.

The main research questions of this study are: What the entrepreneurial innovative network is; how it creates the socio-economic neural system, and how inter-organizational networking becomes a driver of innovation.

The problem is that "creativity" refers to human, while "innovation" is relevant to companies. As a result, the following question arises: How do creative men turn into an "innovative company"? Separate individuals (inventors and researchers) and separate small companies or start-ups characterize the current scenario. They do not interact with each other, but produce innovation (e.g., new technologies and machines, and inventions and new materials) and, in the end, human progress. How does this happen? 
The paper is structured as follows. First, it will illustrate the theoretical foundation of an entrepreneurial innovative network and of SENS-systems. Then, it will provide an analysis of the theoretical bases of the functioning and development of neural networks and self-organized informational systems. Subsequently, it will present the methodology of systems design, based on informational cooperation of neural modules. Finally, based on theoretical insights, the paper will outline the process of the production of information as new knowledge and innovations, and how the process of collective decision-making is realized.

\section{INNOVATION AND CREATIVITY. FROM INDIVIDUALS TO ORGANIZATIONS, FROM COMPETITION TO INTERACTION}

Creativity is usually understood as a process of generating ideas, designing something new, and producing an invention. Traditionally, this process ends up with a novelty that has some value and importance (Amabile, 1996a). As the character of the interaction and relationship between elements has a direct effect on creativity, creativity and social network theories can be integrated (Perry-Smith, 2006). It is obvious that strength of relationships, network position, and external ties could affect individual creative contributions. Some researches consider creativity, productivity, and innovation as a whole concept (Amabile, 1996b). Creativity is not directly related to a specific solution or product. Therefore, the result of creativity is not identical to innovation. Creativity is the sphere of entrepreneurship, because entrepreneurial thinking is based on new ideas about a new product, technology, materials, and methods. The development of innovation can also be studied as a combination of the management of innovation and the decision-making processes within the firm (Izadi et al., 2013). Also, creativity is one of the factors of entrepreneurial success (Baron \& Tang, 2011; Cardon et al., 2013; Gielnik et al., 2012).

However, how does individual creativity form organizational innovation? What is the role of individuals in innovation processes?

Literature research highlights that creativity has an important role in the organizational context (Woodman et al., 1993) or in interpersonal networks (Bissola \& Imperatori, 2011; Lingo \& O’ Mahony, 2010; Perry-Smith, 2006; Spelthann \& Haunschild, 2011).

Creativity stops at the creation of ideas, while innovation is the implementation of the idea and its availability to all people: Customers, manufactures, distributers, and other entrepreneurs. Innovation is the idea that turns into reality.

Today, individual creativity, both at the level of the individual and at the level of individual organizations, does not make sense, as the idea remains on the local level and does not go outside. The idea is preserved, it cannot develop new techniques, technologies, and materials. It cannot be a base for new related ideas. Innovative processes involve all the elements of the innovation system, including generators of ideas, intermediaries (e.g. venture companies), manufacturers, customers, the scientific community, and education. Individual creativity is closed, it is impervious. Instead, collective creativity is open, it is based on the processes of self-organization and initiated from the outside; also, it gives a synergy effect. The result is the creation of specific innovation networks, which are composed of individuals and micro-organizations. The so-called "innovative agents", or "knowledgeable agents" (Giddens, 1984), initiated and supported the process of creating, functioning, and supporting these networks within an organizational structure. These innovative agents, individuals, and small enterprises are in constant interaction. Using the analogy with chemistry, this type of interaction can be defined as "supra-individual" to mean it encompasses such elements as self-recognition, self-organization, collaboration, and corporate decision-making. Thus, the center of the relationship between the elements of the innovation system is displaced, from competition to interaction and collaboration.

Innovative agents initiate the process of generating ideas and creating innovation through the creation of new knowledge. These agents are situated inside organizations, which author study in integrity, within a single business unit. This business unit can be either a SME or a large company, 
as micro-firms and the global corporation. Thus, innovations and new ideas spread from the initial point to another network node and to the outside through the innovative agents, and this process is based on self-organization.

Innovative processes and processes of creating of new are the result of system self-organization. Indeed, these processes are initiated within the system. Also, the inter-organizational communication between system elements, people, and innovation agents creates unique information and communication accumulating in the system and leads ultimately to innovative solutions (innovative "exhaust"). Thus, the nature of innovation is similar to circles on the water: The process starts from the original micro point and expands at the macro and global levels.

The interaction can be of two types: Inter-individual and inter-organizational.

Inter-individual interaction takes place "from individual-to individual." The general laws of social group dynamics are typical of this type of interaction.

In order to study the process of generating ideas at the "individual-individual" level, the author organized an experiment in the group of students at the ITMO University (Russia). Students were asked to search non-standard solutions for typical tasks (e.g., selection of a gift for a friend's birthday or house decoration for the New Year's Eve). The experiment was conducted repeatedly for two years, with the average participation of 465 people. The students worked in teams of 5-7 people, and the time on the solution was about 15 minutes. The results of the experiment are as follows. Each team had an active exchange of information, communication, instant cast, and high creativity. However, no communication occurred between teams, so no output flowed to the outside.

In order to produce the idea and let it out of an organization, communication between teams and between innovative agents should be ensured. These communications bring ideas to the higher level of inter-organization relationships and facilitates the transmission of the idea between organizations, venture companies, banks, customers, and other parties.

Some researchers (Amabile, 1996a; Ketchen et al., 2007; Perry-Smith, 2006; Sapsed et al., 2007; Woodman et al., 1993) studied the specific role of inter-organizations in the early phase of start-ups and in the early phase of the entrepreneurial process. Also, Sapsed et al. (2007) showed how bridging organizations may promote neglected areas of creativity and potential disruptive innovation. These blocked opportunities tend to emerge at the boundaries of Sectoral Systems of Innovation, where old sectors overlap and new trajectories form (Sapsed et al., 2007).

In the early stage of development, each new start-up or enterprise needs not only resources and internal potential. Indeed, more important for future success are the external relationships and interaction between similar enterprises, agents, intermediaries, venture companies, business angels or business incubators for information and knowledge exchange. Entrepreneurial networks are often a source of unique market information as well as of specialized service providers.

An innovation network implies two types of interaction: Inter-individual and inter-organizational. Table 1 shows the difference between individual and collective (inter-individual) approaches to creativity and innovation.

Nevertheless, the following question still needs an answer: How does an individual idea become a collective idea and consistently turns into innovation? The following section explains this process and the mechanism of group dynamics in the innovation process.

\section{THE CONCEPT, STRUCTURE, AND MECHANISM OF THE SOCIO- ECONOMIC NEURAL NETWORK AND OF THE SENS-SYSTEM}

Evidence shows the communication between the elements of the SENS-system; in turn, communication plays an important role in the formation of a unified informational space and innovative entrepreneurial network.

Key conditions of transformation of ideas into innovation are the dissemination of information and knowledge exchange. In addition, the most important factor is joint activity that is the dissemination of 
Table 1. The difference between individual and collective (inter-individual) approaches to creativity and innovation

\begin{tabular}{|c|c|c|}
\hline & Individual approach & Inter-individual approach \\
\hline Subject (person) of the activity & $\begin{array}{l}\text { The sole person-innovator, } \\
\text { "crazy" inventor or researcher, and } \\
\text { Schumpeterian's individuals. }\end{array}$ & $\begin{array}{l}\text { Association of several innovators; } \\
\text { synergy interaction. }\end{array}$ \\
\hline Focus of activity & $\begin{array}{l}\text { Individual development, individual } \\
\text { creativity. }\end{array}$ & $\begin{array}{l}\text { Collective dynamic, collaboration and } \\
\text { collective idea creation }\end{array}$ \\
\hline Focus of the result & Separate idea or invention. & $\begin{array}{l}\text { The process of the diffusion of } \\
\text { innovation }\end{array}$ \\
\hline The process of value creation & $\begin{array}{l}\text { An idea as a separate element does } \\
\text { not have a value because of the lack of } \\
\text { reality. }\end{array}$ & $\begin{array}{l}\text { The value arises from spreading the } \\
\text { initial idea and using it in practice. }\end{array}$ \\
\hline The driver of creation & Outside forces. & $\begin{array}{l}\text { Self-organization, "supra-individual" } \\
\text { interaction. }\end{array}$ \\
\hline
\end{tabular}

information through the implementation of the basic functions and roles of the elements of the system. In this case, each element does its work, and thus they implement functions in a single information space, where the information circulates and accumulates over time. As a result, a qualitative leap is realized (i.e., the amount of information transforms into qualitatively new information). Further processes of creation of innovation are based on self-organization. The distribution of information leads to acceptance of collective decisions, which, in turn, is the basis for generating ideas and innovative solutions.

Holistic socio-economic systems (e.g., company, cluster, SME, micro-organization, and a global company) are a special class of information systems. The following paragraphs explore the information interaction between the elements and the significant role of information in a socio-economic system as an artificial neural network.

Figure 1 shows the set of system elements (or modules of a socio-economic neural networkSENS-modules) that produce information.

An artificial neural network is a system of interaction between artificial neurons; they are designed according to the principle of organization and functioning of biological neural networks. The basic principle of functioning of neural networks is based on the principal of information exchange. Each neural element operates with a limited amount of information and interacts with specified elements. This socio-economic neural network is a SENS-system. Such a system consists of elements that have

Figure 1. The set of system elements (or modules of a socio-economic neural network-SENS-modules) that produce information

Individuals
Enterprises
Intermediaries
Capital providers
Research institutes
Educational institutes
Others...

\begin{tabular}{|c|c|}
\hline $\begin{array}{l}\text { Production of innovation } \\
\text { information } \\
\text { through ... }\end{array}$ & $\begin{array}{l}\text { M\&A } \\
\text { Alliances } \\
\text { Business Accelerators } \\
\text { Business Incubators } \\
\text { Clusters } \\
\text { Joint Venture } \\
\text { Others... }\end{array}$ \\
\hline
\end{tabular}


specified connection and interact between them. These elements are SENS-modules. Each module receives the input signal (i.e., control information, functional). The output information transforms into an output signal as a result of the actions of the elements. The combination of SENS-modules forms a neural network. The solution of complex tasks is to the result of the interaction (collaborations) of separate modules with temporal and spatial coherence of processes. For example, Figure 2 shows a schematic representation of a simple neural network.

Each SENS-module produces information and generates the information flow. The information flow becomes organized as a result of the interaction of modules. The implementation of the principle of "laser" (figure1) is plainly visible, when a great amount of unorganized flow of energy or information is organized into a single beam. The interaction of SENS-modules is carried out through specific communication channels. Each module makes a decision within its own competence, and each element realizes its own functions (i.e., each module is functionally differentiated). Internal controllers realize central collection and processing of information and monitors the operation of the entire system. In the SENS-system, the individuals and information technology are carriers and guardians of information. The problems associated with information flows are solved by technical tools, and the interaction between people is realized through corporate information and social networks.

Communication between elements (modules) could be associative or dissociative (i.e., the neural modules can be combined and decomposed) (figure 3). Thus, an information flow can ensure the connection and disconnection of the elements.

Information exchange is the basis of the process of system development and system dynamics (i.e., it ensures the generation of a something new). In turn, the foundation of any development is something new. This process is accompanied by abrupt transition from a previous state of the system to the next.

Figure 2. Schematic representation of a simple neural network

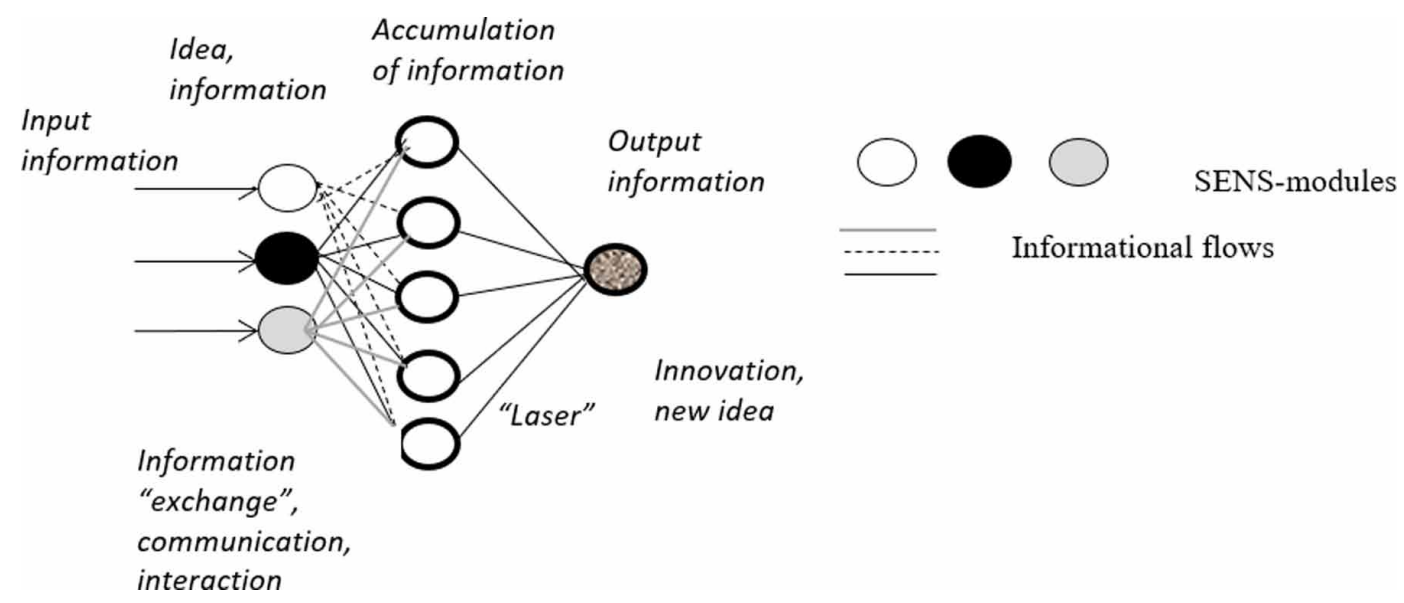

Figure 3. Associative (a) and dissociative (b) interaction of SENS-modules

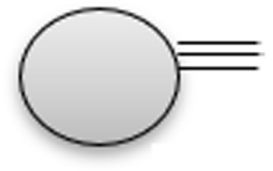

(a)

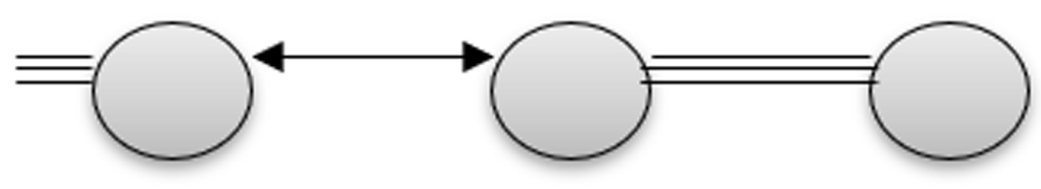

(b) 
The connections between the elements are dynamic and update through the process of development. At the same time, the SENS-system is a recurrent network, that is the output signal (result) is transferred back to input completely or partially (feedback). Thus, as any neural network, the SENS-system is a learning and, most importantly, a self-learning system.

Before proceeding to the theory of corporate collaboration and describing the process of interaction of the elements of the SENS-system, which is accompanied by a transformation of the original information (ideas) to innovation, it is necessary to consider the process of the creation and production of information in the SENS-system.

\section{THE PRODUCTION AND CREATION OF INFORMATION IN THE SENS-SYSTEM}

In order to understand the essence of the process of information production in SENS-systems, the authors will build on the concept of information by Shannon (1948), namely as the number of possible outcomes (Haken, 2005; Shannon, 1948).

The appearance of information is closely associated with the decrease of entropy. For example, in a set of characters, the frequency of appearance of each character has a specific probability $P$. As a result, when the letters of the word are added up, a set of letters will make sense-information occurs. Similarly, the numbers can be considered. Kastler (1967) cites the example with caution: Before selecting a specific code, all code combinations are equally probable. However, once the code is selected, information occurs, and only one combination has value and meaning.

When the authors describe the overall concept of the production of information in the SENSsystems, they will rely on a basic postulate of existence of the relationship between the information processes and evolutionary dynamics of the systems.

The process of development of the system produces the so-called "information system memory" about the past states of the system, which are characterized by a certain set of variables (e.g., economic, social, and commercial). Thus, the system accumulates the set of information data, including statistical data. At the moment of the decision-making on the further evolutionary phase, the system "chooses" a particular path. In this regard, it is important to recall that evolution is an internal process which is initiated exclusively by internal forces and resources of the system. Thus, evolution is a result of a cause and a consequence of objective laws. Herewith, the system uses two sources of information: Internal memory (previous system state) and external environment (threats and opportunities). Information is random; in addition, the individual objectives of managers and the information they have should be considered. The system accumulates the information and produces new information (path selection, removal of information uncertainty), which comes out in the form of a new solution. This solution is not necessarily innovation, but it is inevitably something new (e.g., decision, product, idea, market, needs, and material).

In a SENS-system, the algorithm of production of information is the following. In the development process, the system continuously selects one of the possible states or trajectories of development, and "memorizes" its past state. Thus, data and information about past states accumulate in the system. This means the production of information, when the system makes a selection based on accumulated data. Figure 4 shows the conversion algorithm of information in SENS-systems.

If more than one outcome of an event is viable, it is possible to choose the most preferable. The results obtained are compared with the planned (expected) outcomes, then the strategy adapts. The SENS-system learns when it tries different variants of the strategy or ways to achieve the goals. Thereby, a process of self-learning occurs.

The point of the choosing trajectory is a point of bifurcation, that is the point of duality (or division) of the evolution trajectory with the maximum uncertainty (entropy). In accordance with the theory of information, this uncertainty is removed by the "choice", that means the production (appearance) of information. Thus, the emergence of information is a random process of selection/ 
Figure 4. The conversion algorithm of information in SENS-systems

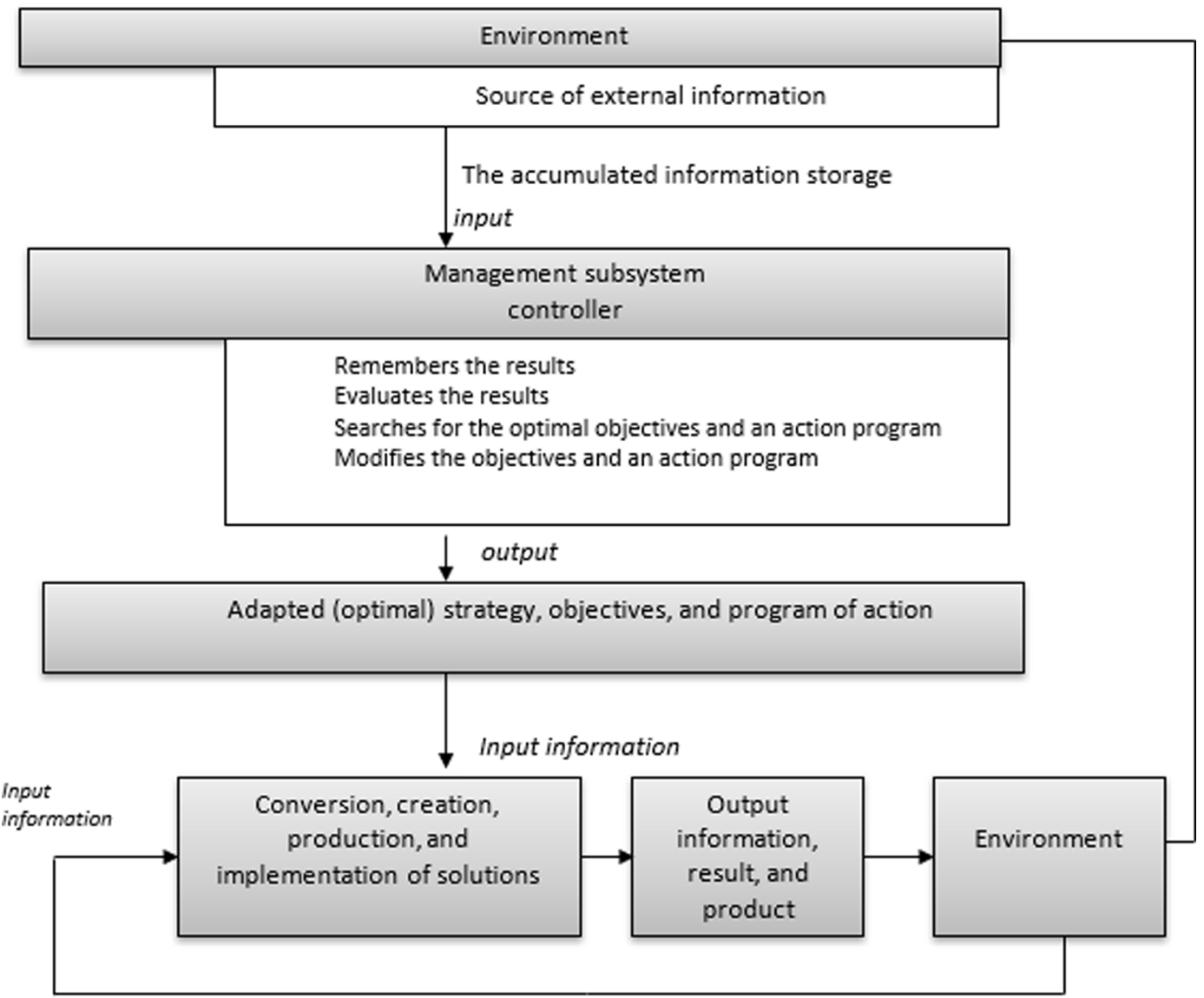

decision-making of the system. Innovation is even a more random and chaotic process, that is, it requires the generation of new information, unknown in the past.

If a random element is introduced in the above algorithm, at some point a branching trajectory of development-the bifurcation point-occurs. Then, the strategic objective and the program of action are chosen, depending on the values of the random parameter that the controller accesses (e.g., the value of stock indices and exchange rates).

Thus, the authors establish the following assumptions for the study of information flows and the process of creation of new (the innovation):

1. Information is created in the system.

2. The system remembers past states, so the future is determined by the past.

3. Information is associated with the differentiation of elements and with the breaking of symmetry of the spatial localization of the elements.

4. Information occurs as a result of interaction between the elements (communications) and, at the same time, determines (defines) the interaction.

Information is a stochastic category (i.e., the probability of the concrete state of the system). A completely random sequence of messages will have maximum of information, since the realization of a concrete sequence of symbols among an array of possibilities is the implementation of one 
state and the only localization system in space. At the same time, the repetition of the same symbols (messages) gives no information. This means that cyclical fluctuations, such as stock indexes, ease the prediction of the future state and the trajectory of development.

The authors can assume that both of these extreme states are impossible, therefore the entrepreneurial system is somewhere in the middle. During the development, enterprises "scan" all possible states; they create information and chaos, due to the change in the probability of a particular state. Meanwhile, the probability of any system states changes from uniform to differentiated, from disordered to structured. This is an innovative development through the production of new.

However, what is the creation of new information? What is the generation of new ideas? This is something that was previously unknown, but is based on accumulated knowledge (information).

It is necessary to fulfill the conditions of information exchange (accumulated knowledge). This requires the implementation of the conditions that the information and knowledge need to be different in each element. Therefore, the information differentiation of system elements has to generate new facts. The presence of external sources of information, which are similar to the external energy of the thermodynamic system Prigozhin, I., \& Stengers, I. (1986), ensure self-sufficiency and completeness of information system elements.

Thus, in their concept, the authors leave the area of the information uniformity (disorder) of the system elements, move to the direction of differentiation of knowledge and exchange of information, and reduce information entropy. Therefore, creating new information and generating innovation require the presence of differentiated elements with different knowledge, skills, and entrepreneurial competences for interaction. The integration of differential information flow and the accumulation of knowledge lead to the "effect of the laser" by means of information interaction of the elements.

In the case of a group of students, for example, the challenge is solving a problem in team. The teams are formed by themselves; functions and roles within the team are distributed randomly, without outside interference (including a teacher). On the basis of the concrete task, knowledge and information exchange occurs among team members; everyone has his/her own accumulated life experience and knowledge. The decision takes on average 15-30 minutes, and every team produces a joint determination. Indeed, the students' task is quite simple. Thus, the process of finding a solution is random, and it suddenly emerges from the discussion. The authors can logically assume that, in the business sphere, the mechanism is absolutely the same. Nevertheless, it will certainly take more time, as the tasks are more difficult, the amount of information is greater, and the system has a larger number of elements and external ties. Therefore, the generation of the fundamentally new is impossible without information exchange between the elements. The information they have is based on experience and knowledge. The more complex the task, the more information the elements need to process, and the more various alternative solutions they have to develop, before finding the correct one. As a result, this requires a growing extension of time (figure 5).

Therefore, the process of production of information is the process of differentiation of information messages (symbols). For example, a set of unordered elements can illustrate this. In the information chaos, no structured information is available, since each element is identical to another, as clones. In fact, is it possible to order exactly the same set of elements-clones as, for example, in figure 6 ?

It is interesting to try to move their places repeatedly, observe if something changes, and wonder what happens if one element-clone is moved instead of another or if the number of elements-clones increases to 1000000, for example. Another example can be the sequence of symbols of type AAAA. This sequence describes the state of the system as deterministic, predictable, unorganized, and unstructured. The value of entropy is maximum. All the states of the system have the same probability. In relation to entrepreneurial systems, this means that an enterprise is stable and deterministic; it develops cyclically. No innovations occur because all processes are determined.

In order to solve this problem and to understand the relationship between information, differentiation, and innovation, it is necessary to understand what is an ordering. The essence of ordering suggests that a hierarchy of distributed system elements is built on any basis, vertically 
Figure 5. Schematic representation of the process of creation, accumulation, and transformation of information into an innovative idea, as a result of the bifurcation leap

accumulated knowledge and "life experience"

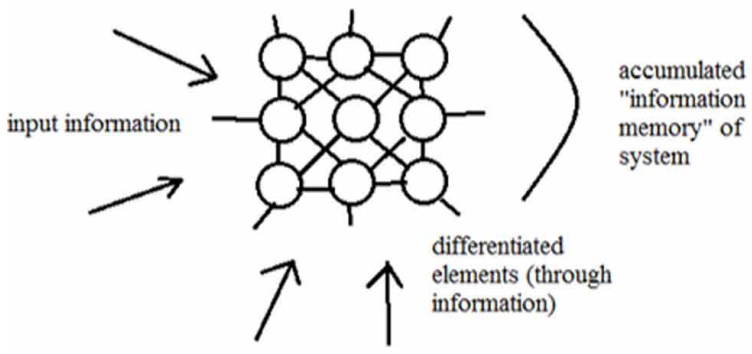

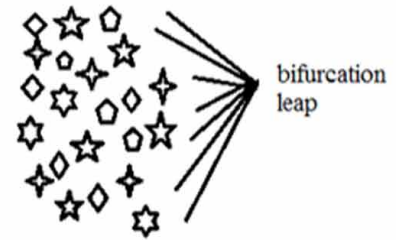

alternative solutions

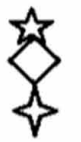

decision, the specific combination, information certainty

Figure 6. Schematic representation of elements-clones of a system
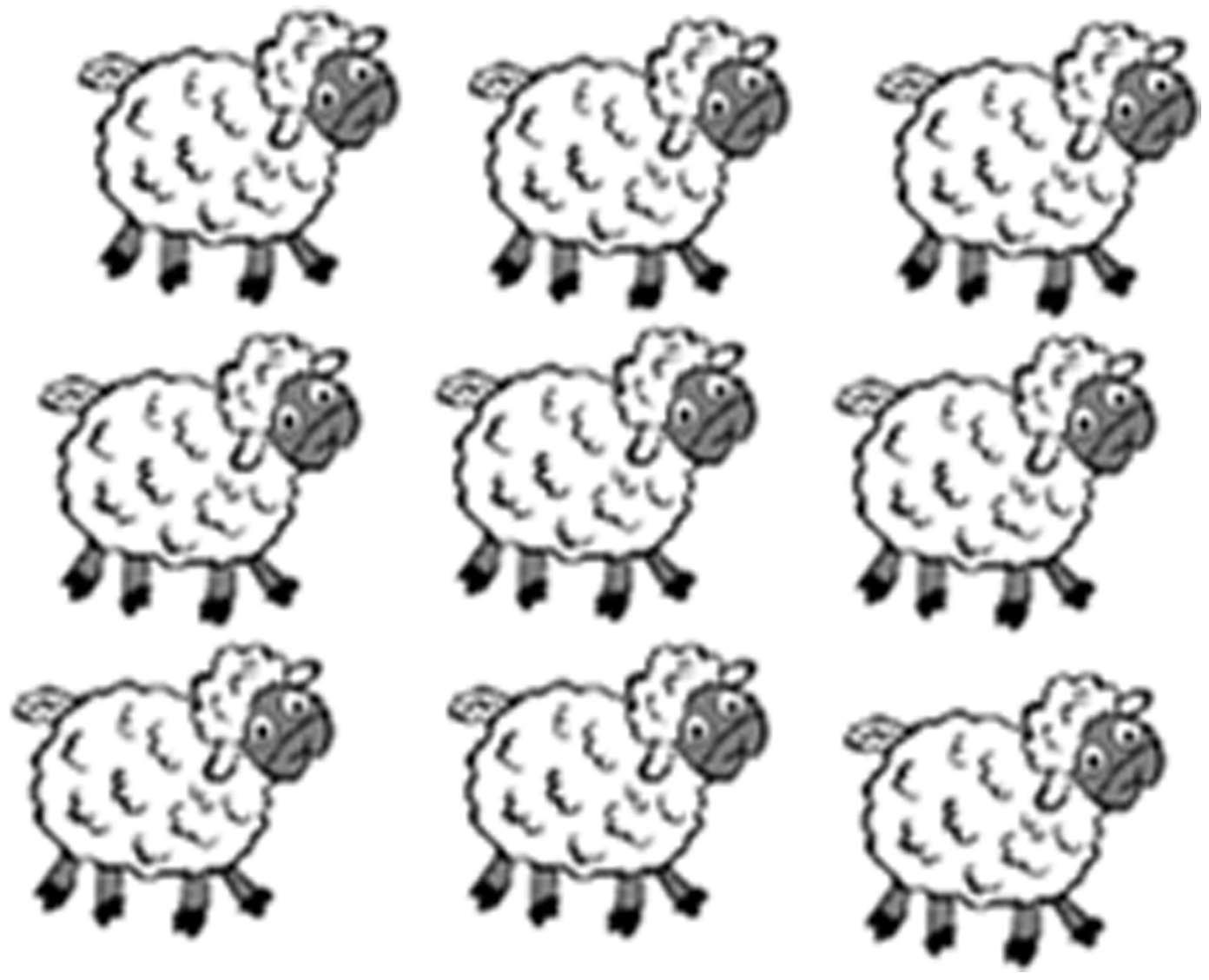

(i.e., hierarchical differentiation-who reports to who, subordination, and who is more important) and horizontally (i.e., functional differentiation-who solves which problems). In other words, an ordered structure is the result of the creation of inequality of the elements. What does this have to do with information? 
A priori, a necessary condition for the existence of the system consists in the links and interactions between system elements. Anyhow, the interaction between the clones is impossible, as absolute identity assumes that elements are autonomous and they do not need each other. It is impossible to assemble a complicated device from exactly the same parts.

In order to implement the interaction between the elements within the system and to achieve certain goals (e.g., system objectives, ensuring the survival of the system and its viability, and local purpose of the elements), each element must carry some information that is important and necessary for other elements to do their work. This information appears directly in the information flow, and through the functions and tasks of each element. The authors conclude that the ordering/structuring of a system is the information differentiation of its elements. In other words, information, as a synonym of order, is born from disorder and chaos. Information production is closely linked to the creation of new structures, as the differentiation of the elements is the structuring of the system. Therefore, the authors state that information is the creation of the new.

Thus, the logical conclusion is that the creation of new, creative, and innovative processes is directly connected with the emergence of information and with collective dynamics in social systems. The creation of the new and innovation cannot be realized without the cooperation with other companies. This is due to the nature of information flows in the business system: Systems are open and informative, and they do not exist outside the information space.

The use of the sequence of characters will complete the example. The sequence of symbols $A B C D E F G$ describes the state of the system as uncertain, non-deterministic, and chaotic. Hence, a logical and natural task is ordering the elements, structuring the information flow, and eliminating uncertainty, as figures 7 and 8 show:

This pattern is more meaningful and immediately reflects that it refers to an organized set of elements. Each element carries information and has an essential role in the system as a whole. Consequently, the differentiation and the ordering of the elements in the information systems, which include the socio-economic system, is the process of creating information, that is information is opposite to chaos and innovation is created from chaos.

However, the most interesting outcome is that the new creation is not a result of external pressure, but of the self-organization ("principle of information laser") and collaboration of the system itself.

Figure 7. Ordered set of system elements

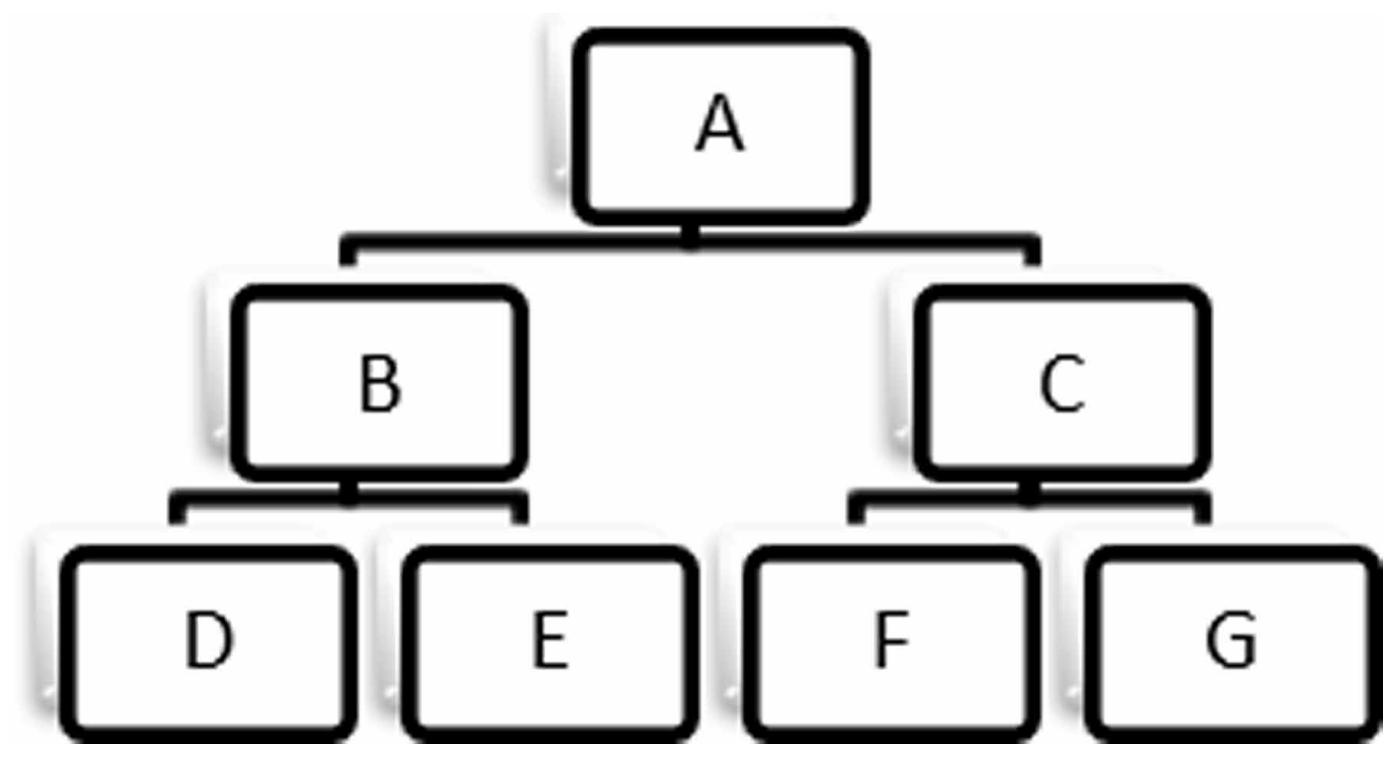


Figure 8.

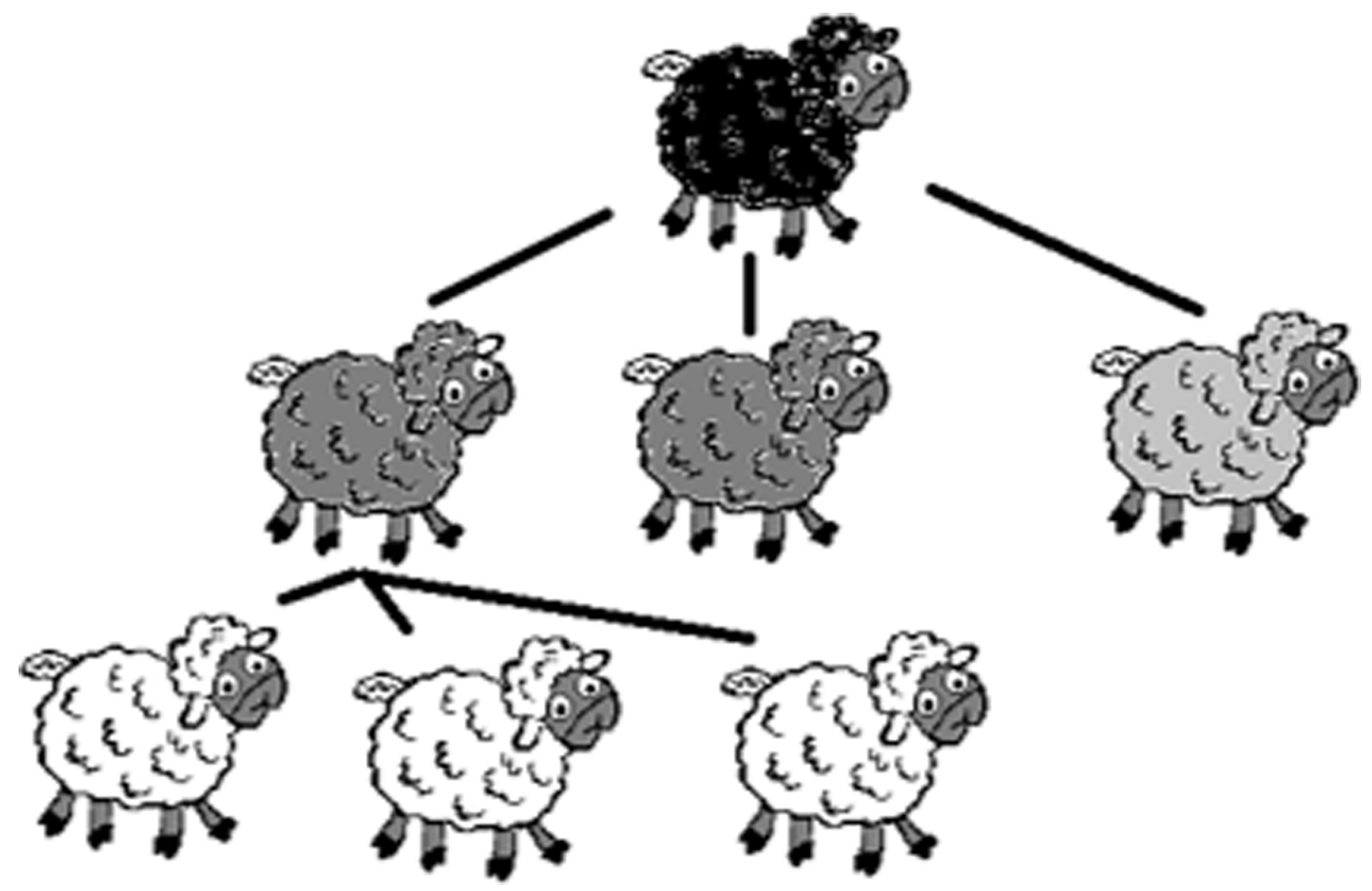

\section{THE THEORY OF SELF-ORGANIZATION AND CORPORATE COLLABORATION OF SENS-SYSTEMS}

Corporate collaboration is the process of cooperation and interaction of two or more elements of the socio-economic system. The mechanism of collaboration and self-organization of a business system is based on collective dynamics: A simple behavior of elements (individuals) generates a complex behavior of the company as a system.

The mechanism of corporate collaboration of self-organizing complex systems is based on the following steps:

1. Each element interacts with a limited number of elements that are directly related through the functioning and are unified by the local goal with "neighbouring" elements.

Studies show that the number of links between elements of a complex self-organizing system must be constant. Herewith, the remoteness of the elements does not matter. Figure 9 shows examples of interaction elements in the system with low and high density of spatial arrangement of the elements.

2. The collective decision-making is implemented as a collective self-consciousness.

Figure 10 illustrates the scheme of the collective dynamics and collective decision-making. The socio-economic system self-organizes and develops, that is it creates innovation.

The leader (i.e., the innovative agent, that can be an individual or a leading company) makes the first decision. Then, some other members of the group join this decision. When the group will support the leader's decision, the processes of self-identity, self-organization, and self-recognition manifest. This is the moment of collective decision-making and self-organization. A relevant example 
Figure 9. Examples of interaction elements in the system with low and high density of spatial arrangement of the elements

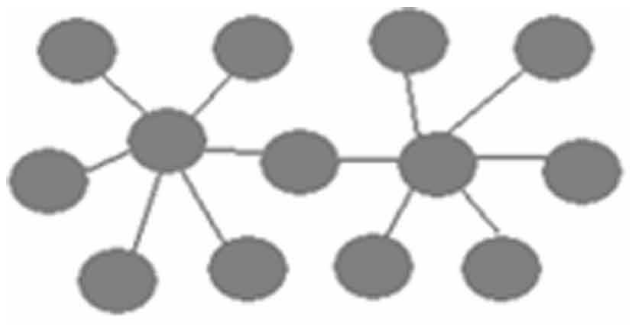

a)

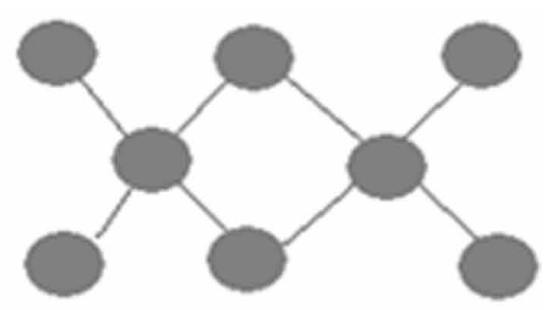

b)

Low density of spatial arrangement of the elements: a)hexagonal network b)rectangular network

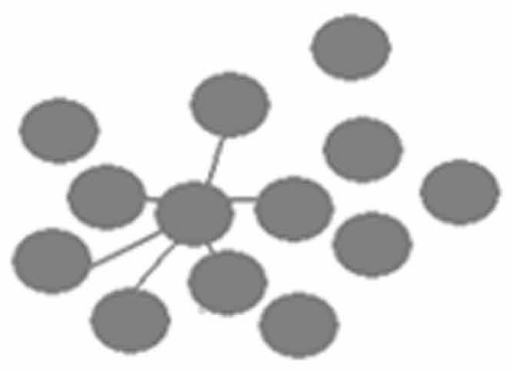

High density of spatial arrangement of the elements (chaotic)

Figure 10. The scheme of the collective dynamics and collective decision-making

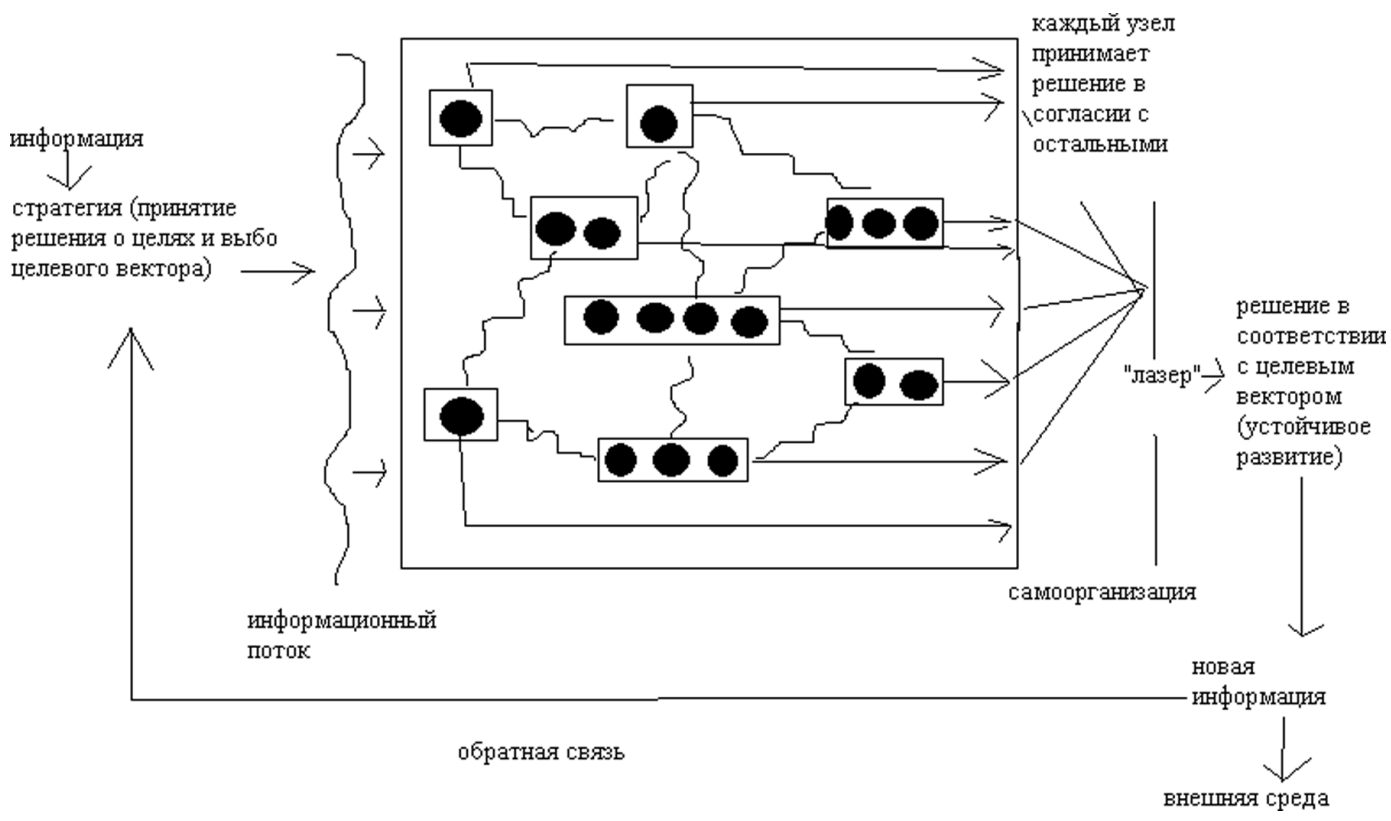


can be the self-organization of consumers and of financial and stock markets, when a leader's actions determine the direction of development and force other companies to catch up and follow him/her in a number of areas (e.g., produced assortment, marketing strategies, and use of technology and equipment in the production process). It is obvious that a necessary condition for self-organization is non-interference (or slight interference) of the controller, such as the state, the central bank or other regulatory industrial organizations.

The leader has a maximum amount of resources (e.g., financial and informational) at his/her disposal. The main condition of self-organization is corporate collaboration and the exchange of information flows between elements. If the elements are competing, no information interaction takes place and the information flow is diffused (not "information laser"). Therefore, the process of selforganization is not implemented.

The idea is generated in a certain relative point, that is the so-called "innovative agent." It can be an individuum, a group of people, or a team. Each element of the system interacts with a limited number of neighboring elements through the performance of their professional tasks or by providing information. At some temporary point, a "jump" occurs: The idea "pops up" from the point where it was created, as ping-pong, and gradually spans the entire system in a ricochet, involving all over in the innovation process. Actually, this is an act of collective decision-making and collective collaboration. Examples of such systems are clusters of socio-economic systems, that clearly define their members, have their functions distributed among cluster members, and allow for clear connections between their members. The next section will provide a more detailed example of these clusters. Thus, the authors can draw a conclusion about another condition of corporate collaboration: The division of labor (i.e., functions), that is, the concentration of each element on its core competencies.

The basic components of a corporate collaboration are:

1. Information potential (the level of communications). This means: The number of connections, the efficiency of connections, a set of information sources, IT, methods, and forms of interaction between elements.

2. Production and technological cooperation (i.e., number of contracts and the share, or contribution weight, of each element in the overall result).

3. The uniqueness of the product of each element.

4. Innovative capacity, as the capacity and the ability to generate innovations.

Self-organization is not programmable; it is based on collaboration elements. The interaction between the elements in the process of self-organization can be of the following types:

- Active (e.g., production synergy-most often, reduction of costs, specialization of elements, merging of the achievements, and best practices).

- $\quad$ Social (i.e., global social development and social planning-social synergy effect).

- Information (i.e., integration of information flows, knowledge, innovative potential, creation of the new, and innovative potential).

Thus, corporate collaboration is implemented through functional action, social interaction (i.e., the interaction of individuals and social groups), and communication (i.e., exchange of information between the various elements of the business system and with the external environment). Corporate collaboration is realizable only in the context of self-organization. It means that the interaction between the elements of the system is a spontaneous process, which is initiated inside the system and under the influence of external and internal factors. The process of collaboration shows processes that are similar to the processes of the competition: Elements compete among themselves from the point of view of their usefulness for the system and system-wide goals. 
The more important the role of the element in the system to ensure its viability and vitality, the more the element has a chance to achieve its own goals. It is interesting that at a constant number of elements the number of connections is constant, but the quality and form of interaction can change. This is necessary to keep in mind during the organization of the business processes, business structures, and the improvement of the efficiency of their functioning.

\section{APPLICATION OF THE THEORY IN PRACTICE: ILLUSTRATION AND STUDY OF CLUSTERS OF SOCIO-ECONOMIC SYSTEMS}

In the following, the clusters located in different regions of the Russian Federation are analyzed, in order to study the authors' hypothesis in practice. To this date, the cluster form of organization and functioning of socio-economic systems is the most appropriate innovative neural network. A cluster is a voluntary association of companies which is based on cooperation and self-organization; they have their own rules and norms of functioning.

The cluster consists of several companies united by geographic proximity and by unity of the technological chain of production of a product or service. Clusters are created on the basis of voluntary association, usually with the aim of optimizing resources and increasing the effectiveness of each element of the cluster, as a result of the interaction and collaboration with others.

As the main empirical data, the authors used data from the official websites of the clusters.

The authors studied just 106 clusters. The minimum number of participants was 10 and the maximum was 213 .

The main areas of study were:

- The reasons why enterprises united in the cluster.

- The level of concentration on core competencies.

- The nature and intensity of relationships between the elements of the cluster.

The most important condition for the creation of SENS-systems consists in the interaction and relationships between the elements of the cluster, and the presence of key competences in each element, which allow to create unique business value for the system as a whole). Therefore, the authors will hold to these positions in their study.

First of all, it is necessary to list the companies' aims to join in the cluster. Target analysis will allow to understand the expectations that the companies which united in the cluster had and what they mean by the cluster:

1. Creation of a single industrial manufacturing complex, with interconnected production; this goal is mentioned by all the participants.

2. Production cooperation and interaction.

3. Development and modernization through collaboration.

4. Improving the competitiveness of the complex (e.g., industrial) region of the country (i.e., at the meso level).

5. Increase of competitiveness as a result of the interaction within a single technological chain plus consulting and education.

6. Creation of a closed production cycle (i.e., chain): University, R\&D, manufacturing, transportation, and production infrastructure.

7. Collection of the company's intellectual, scientific, innovative, educational, and administrative potential.

8. Cost reduction in the processing chain.

9. Development and implementation of joint projects. 
10. Growth and competitiveness of the regional economy through commercialization of innovations.

11. Development of common rules, standards, and techniques.

12. Promotion of sustainable development of the industry.

13. Improvement of competitiveness through the concentration of resources and optimization of the development areas.

14. Vertical integration.

It is evident that the main aim is the creation of a unified informational and technological space, in which all participants can achieve their own goals and improve efficiency by combining efforts and mutual beneficial collaboration.

Next, determine the level of concentration on core competencies is determined. The authors assume that key competencies are the activity of the cluster, which is stated as the primary activity (i.e., production of product or provision of services).

The study identified three main groups of clusters:

1. Clusters with high diversification of activities and a wide range of additional competences $(46,22 \%)$.

2. Clusters with related additional competencies (i.e., complementary, serving the major activity) $(29,25 \%)$.

3. Clusters with focus only on core competencies $(24,53 \%)$.

Figure 11 shows the distribution.

A misalignment is evident in the main objectives: On the one hand, companies declare the integration for synergy effects, which suggests focus on key competencies, and on the other hand a high diversification of activities does not allow to concentrate on the main activity and optimize the

Figure 11. The distribution of clusters on level of concentration of key competencies

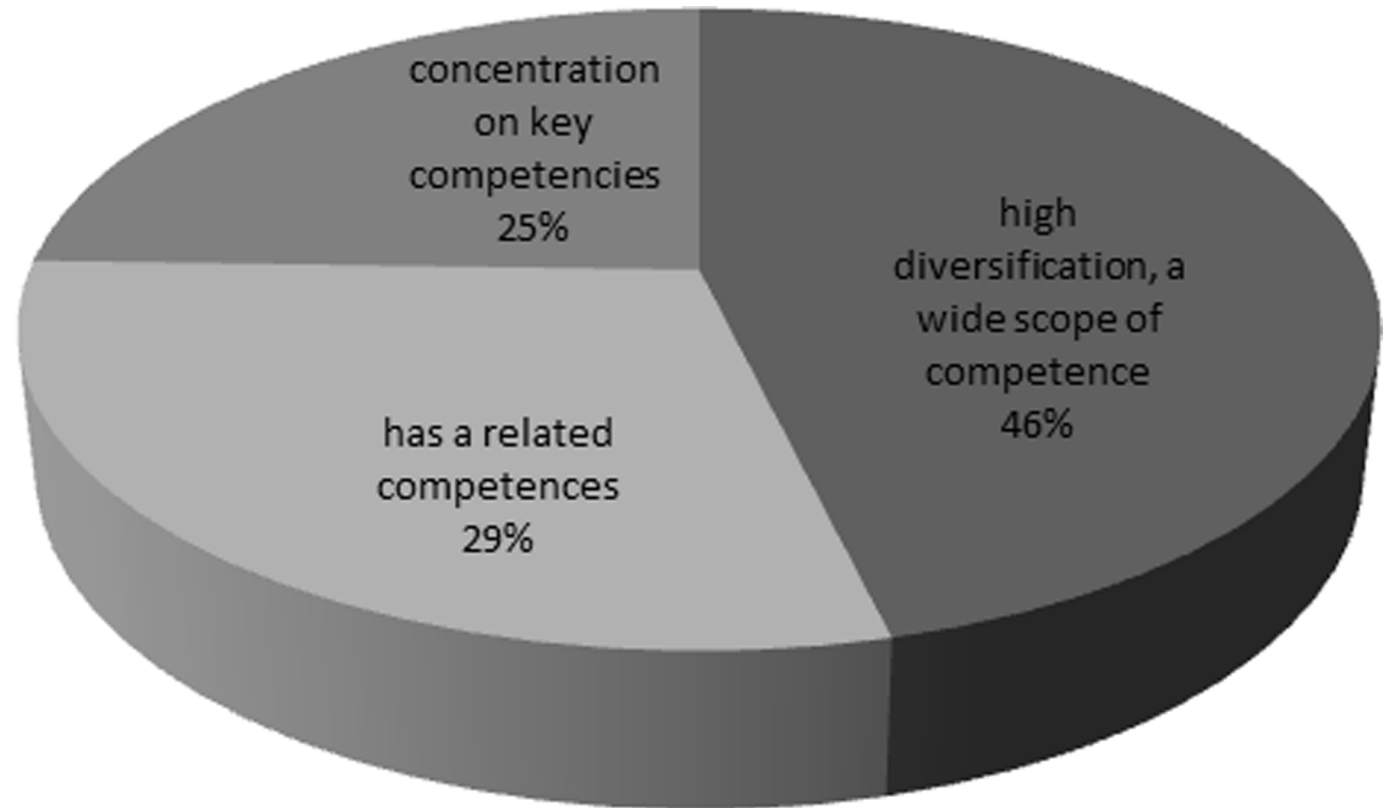

The level of concentration on key competencies 
cost of the product and of the resources. Most companies (46\%) have broad areas of activity. Thus, the companies which are included in the cluster lose the main advantage of cluster forms of organization, from the point of view of systems theory and neural networks. Specifically, they lose cooperation on key competencies and the establishment of interrelations leading to the multiplication of efficiency indicators and to the increasing the effectiveness of each element of the cluster, as a result of the growth of the effectiveness of the cluster as a whole.

In the study of clusters as a SENS-system, the authors are interested, first of all, in the intensity and strength of the relationships between elements within the cluster, and between the cluster and the external environment. In accordance with the general theory of systems, the internal connection between the elements should be stronger than the external, which will ensure the unity and integrity of the system. In addition, internal communication and interaction between the nodes of the network are a key factors in the effectiveness of the network.

Thus, it is necessary to determine the two key indicators of the relationships/interactions between the elements of a cluster:

- The intensity (i.e., strength) of the connection or interaction.

- The level and nature of influence of connections on the overall performance of the cluster and the contribution of each element to the efficiency of the cluster as a whole.

As the authors revealed, the interaction between the elements of the cluster, and so between the nodes of the neural network, is performed in the following directions:

1. Between identical elements of a cluster "firm-to-firm" (F2F), that means interaction between "clones" that implement the same functions in the same sphere of activity or industry.

2. Between neighboring related elements "firm-to-company" (F2C), that is between the elements involved in a concrete process chain or production cycle.

3. Between the elements and the external environment "firm-to-environment" (F2E) (e.g., public authorities, consumers, competitors, and resource providers).

The unifying factors are the creation of a single technological chain, the presence of additional competencies and services for the cluster, in terms of additional functions, common goal, common strategy, and priorities for the development of the cluster.

On the basis of the research, the authors can identify several types of clusters:

1. A symbiotic form of the cluster. This cluster includes companies with a high degree of concentration on core competencies. They have a high degree of influence on the overall result and a strong intra-cluster communication between members. In this form of clusters, companies can achieve the maximum of synergy.

2. "In-active-search" cluster. The members of this cluster have their core competencies, but they have not established cooperation with other partners yet. Most of the members are microbusinesses or SMEs which joined cluster with an uncertain objective.

3. The Cluster for "mutual provision of services by independent companies". Cluster members are independent businesses which have high differentiated competences and receive benefits when the join their forces in unions and alliances.

4. The "formal cluster". Companies are members of the cluster, but act mostly on their own and receive some benefits because they access the capabilities of the cluster. The slogan is "I can do it myself, but can provide the opportunity for you to help me". 
5. The cluster for the "optimization of functioning". Companies join the cluster to optimize the cost of the resources, to create the infrastructure for its primary activities, and to access the resources. Typical examples are industrial enterprises and educational institutions.

6. The "barter" cluster. It refers to the provision of mutual services and beneficial cooperation.

The following matrix illustrates the distribution of the types of cluster (table 2)

The interaction between the elements of a cluster makes sense, if the synergy effect is reached, but still the question remains: How is it possible to define it? How reasonable is an association or joining a cluster for a particular company?

In the following, the authors will consider several possible variants of calculating the synergy effect. In general, the synergy effect reflects the result of the interaction between various elements of the system. The result of this interaction exceeds the sum of the results of each element, if they had acted independently (see Equation 1):

Sinerg $=\left(\mathrm{R}_{1}+\mathrm{R}_{2}+\ldots+\mathrm{R}_{\mathrm{n}}\right) \times \mathrm{M}_{\text {sinerg }}$

$M_{\text {sinerg }}$ - the multiplier considering the multiplication results;

$R_{n}-$ the result of the acting of each element.

If Sinerg $>\sum R_{n}$, this indicates a high level of interaction and the achievement of synergies.

\section{The First Approach to the Definition of Synergetic Effect-Differential}

The essence of a synergistic effect is to increment the result for each element of the system on the value $M_{\text {sinerg }}$ with respect to the usual result, that is, when the elements do not interact with each other.

For the purposes of further analysis, the authors will treat the result of the action of the system as a conditional result, which can be represented in practical calculations in the form of traditional financial and economic indicators of the enterprise's activity, as well as any other commercial, social, and other indices, depending on the task at hand.

Let's denote the combined result of several systems through $R$, partial results of each element $r_{l}, r_{2}, \ldots r_{n} ; n-$ the number of elements of the cluster.

Table 2. Matrix of the distribution of the types of cluster

\begin{tabular}{|l|l|l|l|l|}
\hline $\begin{array}{l}\text { Intensity (strength) of the } \\
\text { connection or interaction }\end{array}$ & High & $\begin{array}{l}\text { Functional synergy, } \\
\text { a symbiotic form } \\
\text { of cluster, and } \\
\text { predominance of } \\
\text { relations "F2C". }\end{array}$ & $\begin{array}{l}\text { Barter } \\
\text { search for the best } \\
\text { forms of interaction } \\
\text { between the members } \\
\text { of the cluster. }\end{array}$ & $\begin{array}{l}\text { Joint ventures, alliances, } \\
\text { unions, cluster type } \\
\text { "mutual provision } \\
\text { of services of the } \\
\text { independent companies," } \\
\text { and prevalence of F2F } \\
\text { relations. }\end{array}$ \\
\cline { 2 - 5 } & Low & $\begin{array}{l}\text { Company with the } \\
\text { status "in active } \\
\text { search". Transitional } \\
\text { stage. }\end{array}$ & $\begin{array}{l}\text { Undefined core } \\
\text { competencies and } \\
\text { "optimization of } \\
\text { functioning". }\end{array}$ & $\begin{array}{l}\text { Prevailing of F2E relations } \\
\text { and formal cluster. }\end{array}$ \\
\cline { 2 - 5 } & & $\begin{array}{l}\text { Concentration on core } \\
\text { competencies }\end{array}$ & $\begin{array}{l}\text { Related competencies } \\
\text { competencies }\end{array}$ & $\begin{array}{l}\text { The presence of additional } \\
\text { comples }\end{array}$ \\
\hline & The level of diversification of competences & Strong \\
\hline
\end{tabular}


If the combined result is denoted as a function of variables $\{r\}$, the increment of the partial result of the first element $r l$ gives the partial increment of the function $R=f(r)$ on $r_{1}\left(\Delta r_{1}\right)$ :

$\Delta_{r_{1}} R=f\left(r_{1}+\Delta r_{1}\right)-f\left(r_{1}\right)$

or, taking into account several elements:

$\Delta_{r_{1}} R=f\left(r_{1}+\Delta r_{1}, r_{2}, \ldots, r_{n}\right)-f\left(r_{1}, r_{2}, \ldots, r_{n}\right)$

In turn, the increment of the second element will give the increment of the aggregate result, according to Equation (4):

$\Delta_{r_{2}} R=f\left(r_{1}, r_{2}+\Delta r_{2}, \ldots, r_{n}\right)-f\left(r_{1}, r_{2}, \ldots, r_{n}\right)$

and so on.

The total increment is expressed by the resultant function as follows:

$\Delta R=f\left(r_{1}+\Delta r_{1}, r_{2}+\Delta r_{2}, \ldots, r_{n}+\Delta r_{n}\right)-f\left(r_{1}, r_{2}, \ldots, r_{n}\right)$

The increment of the function $R$ on argument $r_{1}, r_{2}, \ldots r_{n}$ gives partial derivative on $r_{1}, r_{2}, \ldots r_{n}$ on $R$ :

$R^{\prime}\left(r_{1}\right)=\lim _{r \rightarrow 0} \frac{\Delta R}{\Delta r_{1}}$

or

$R^{\prime}\left(r_{1}\right)=\lim _{r \rightarrow 0} \frac{f\left(r_{1}+\Delta r_{1}\right)-f\left(r_{1}\right)}{\Delta r_{1}}$

Thus, if the function of the aggregate result is differentiable (depending on the selected indicator), then a synergy effect can be determined via derivatives of the resulting functions $R$.

Next, if the increment of the variable $r_{l}, r_{2}, \ldots r_{n}$ is taken as differential $(\Delta r=d r)$ :

$d R=A \Delta r$

In accordance with the definition of differentiability of a function $A=f^{\prime}\left(r_{n}\right) \Delta r$

Then:

$d R=f^{\prime}\left(r_{1}\right) d r$

The desired differential will be a synergy effect: 


$$
\text { Sinerg }=d R=f^{\prime}\left(r_{1}, r_{2}, \ldots, r_{n}\right) d R
$$

\section{The Second Approach of the Synergistic Effect-Cost-Estimate Approach}

This approach is clearer and simpler and involves the identification of a synergistic effect, based on the value (or capitalization) of the companies involved in the cluster. Then, a synergistic effect is defined as the difference between the value of the elements (i.e., enterprises, firms, and companies) after the merger and the sum of their values before the merger:

$$
\text { Sinerg }=\Delta \text { Csinerg }=(C 1+C 2) S-(C 1+C 2)
$$

where $C_{1}, C_{2},-$ value (capitalization) of companies.

$S$ - multiplier that increases the value of the elements of the system.

If $\Delta C_{\text {sinerg }}$ has a positive value, a synergy effect is achieved.

\section{The Third Approach of the Synergistic Effect is Based on the Determination of the Effectiveness of Each Element/Company in the Cluster}

It is necessary to correlate the performance of each company in the cluster without association and their effectiveness in the cluster.

In order to simplify the calculations for further analysis, the authors use a traditional measure of the effectiveness of the conditional profitability (i.e., the ratio of the conditional profit and conditional costs). In practical calculations, the value of the numerator-net profit-can be different (i.e., gross, net profit, sales revenue, and income from investments and other invested funds) and the denominator can represent the cost of the assets, the company's fixed assets, subject to or without regard to management costs and receivables, and cost.

The calculation algorithm is the following. The conditional profitability of each element is calculated, regardless of its participation in the cluster. The result is a set $P_{1}, P_{2}, P_{3}, \ldots, P_{n}$, where $n$ is the number of elements (i.e., companies) included in the cluster.

Since the authors operate with a dynamic economic performance, it is logical to calculate the chronological average for the period $t$. If the measurement results are implemented in equal periods, the chronological average is a simple calculation:

$$
\bar{P}=\frac{\frac{P_{1}}{2}+P_{2}+\ldots+P_{k-1}+\frac{P_{k}}{2}}{k-1}
$$

$k$ - a number of measurements;

$p-$ the result (in this case profitability) on each date of measurement.

If the measurement results are implemented in unequal intervals of time, then the formula chronological weighted is used: 


$$
\bar{P}=\frac{\sum \overline{\left(P_{i}+P_{i+1}\right)} \times t_{i}}{\sum t_{i}}
$$

Next, it is necessary to determine the aggregate result of the cluster. When the income and the assets of the members of the cluster are merged, the aggregate performance is defined as the ratio of the total profits of all participating companies and their total costs. Let's correlate the aggregate performance and the average performance of each element:

$$
S_{1}=\frac{\text { cluster }}{1} ; S_{2}=\frac{\text { cluster }}{2} \text { and so on. }
$$

Performance indicators of the cluster can be:

- Profit (total rate of return)

- Market share

- Sustainability

- Growth in the number of companies

- Increase the number of staff

- Innovation

- Other

If the value $S>1$, it is possible to conclude that the performance of the company in the merger is more profitable than separately. Then it is logical to assume that if the total performance of the cluster is calculated, sequentially excluding each participant, it is possible to identify those elements which lead to lower aggregate performance and that can therefore be excluded from the cluster.

Based on the study and on the observation that a low level of concentration on core competencies occurs (the focus of this research is mainly on business clones), a natural question arises: Why are small companies so interested in joining a cluster, despite the fact that, by doing so, they increase the competitive density and actually have to be in close proximity with its competitors?

The answer could be that Many SMEs and microbusinesses are included in the cluster, despite the high competitive density and because of the general principles of survival: a larger "unit", as it is the case in this research, is less likely to be eaten than a small one. Then, the same functions of the companies-clones are distributed for the needs of the cluster as a whole, thereby giving all the opportunity to each element to choose a root function (or a set of such functions). This somehow allows companies to reduce the cost of resources and increase their overall efficiency.

\section{CONCLUSION}

The results of this study found the clear link between innovation and corporate collaboration. The authors found that the essence of innovation is transformation of an initial idea into some decision, and implementation of this decision in the reality.

If creativity is considered in the context of innovation, creativity is the act of collective decisionmaking: some idea that appears in some point, or in some inventor's or researcher's brain, has to go beyond their laboratory in order to turn into innovation.

Innovation is a specific form of entrepreneurial activity. Individual creativity must be transformed into corporate creativity, the idea should spread into the environment, and then it becomes an innovation. Innovative agents will help the idea to arise and to distribute around the world. Innovation 
and the process of creating the new is a process of self-organization, as it is initiated within the system as a response to external challenge. The creation of an idea initiates the process of information exchange within an organization ("circles on the water"). Investigating this process, the authors have concluded that an individual approach to the creation of innovations is obsolete in comparison with the collective (inter-individual). Thus, they have approached the study of socio-economic systems as neural networks.

Each socio-economic system is an artificial neural network-SENS-system. The main condition of creation of innovations consists in dissemination of information and knowledge sharing. The functioning of these systems is closely connected with information distribution and ideas diffusion for the creation of the "information laser effect". The authors considered the process of production and spreading of information in the SENS-systems and found the link between information, collective decision making, and creation of the new.

SENS-systems are a special type of these systems; their function and action are based on selforganization, corporate collaboration, and interaction between their elements. The authors found that self-organization is a non-programming process that is based on collective dynamic. Also, innovation is a result of collective collaboration, which means active, social, and information interaction. The mechanism of corporate collaboration is the sequential process of idea creation, spreading of this idea to the neighborhood elements, collective decision-making, and appearance of the "information laser" or innovation.

The designing of socio-economic systems as neural networks is one of the most interesting tasks of modern science and management practices. The application of the principles of functioning and development of neural networks in socio-economic systems can increase their effectiveness and innovativeness in modern society and economy.

Further research should be devoted to the study of distribution of the cluster types, the dynamics of how one type transforms into another, the search of formulas to calculate intensity and power relations, and their influence on the overall result. 


\section{REFERENCES}

Amabile, T. M. (1996a). Creativity in context: Update to the social psychology of creativity. United States: Westview Press.

Amabile, T. M. (1996b). Creativity and innovation in organizations. Boston: Harvard Business School.

Baron, R. A., \& Tang, J. (2011). The role of entrepreneurs in firm-level innovation: Joint effects of positive affect, creativity, and environmental dynamism. Journal of Business Venturing, 26(1), 49-60. doi:10.1016/j. jbusvent.2009.06.002

Bissola, R., \& Imperatori, B. (2011). Organizing individual and collective creativity: Flying in the face of creativity clichés. Creativity and Innovation Management, 20(2), 77-89. doi:10.1111/j.1467-8691.2011.00597.x

Cardon, M. S., Gregoire, D. A., Stevens, C. E., \& Patel, P. C. (2013). Measuring entrepreneurial passion: Conceptual foundations and scale validation. Journal of Business Venturing, 28(3), 373-396. doi:10.1016/j. jbusvent.2012.03.003

Giddens, A. (1984). The constitution of society: Outline of the theory of structuration. Berkeley, CA: University of California Press.

Haken, H. (2005). Information and self-organization. A Macroscopic approach to complex systems. Moscow: KomKniga.

Izadi, A., Zarrabi, F., \& Zarrabi, F. (2013). Firm-Level Innovation Models. Procedia: Social and Behavioral Sciences, 75, 146-153. doi:10.1016/j.sbspro.2013.04.017

Kastler, G. (1967). The emergence of biological organization. Moscow: EKSMO.

Ketchen, D. J., Ireland, R. D., \& Snow, C. C. (2007). Strategic entrepreneurship, collaborative innovation, and wealth creation. Strategic Entrepreneurship Journal, 1(3-4), 371-385. doi:10.1002/sej.20

Lingo, E. L., \& O’Mahony, S. (2010). Nexus work: Brokerage on creative projects. Administrative Science Quarterly, 55(1), 47-81. doi:10.2189/asqu.2010.55.1.47

Perry-Smith, J. E. (2006). Social yet creative: The role of social relationships in facilitating individual creativity. Academy of Management Journal, 49(1), 85-101. doi:10.5465/amj.2006.20785503

Prigozhin, I., \& Stengers, I. (1986). Order from chaos. Man's new dialogue with nature. Moscow: Progress.

Sapsed, J., Grantham, A., \& DeFillippi, R. (2007). A bridge over troubled waters: Bridging organisations and entrepreneurial opportunities in emerging sectors. Research Policy, 36(9), 1314-1334. doi:10.1016/j. respol.2007.05.003

Shannon, K. (1948). A mathematical theory of communication. The Bell System Technical Journal, 27(3), 379-423. doi:10.1002/j.1538-7305.1948.tb01338.x

Spelthann, V., \& Haunschild, A. (2011). Organizational Creativity in Heterarchies: The Case of VFX Production. Creativity and Innovation Management, 20(2), 100-107. doi:10.1111/j.1467-8691.2011.00598.x

Woodman, R. W., Sawyer, J. E., \& Griffin, R. W. (1993). Toward a theory of organizational creativity. Academy of Management Review, 18(2), 293-321. doi:10.5465/amr.1993.3997517 
Olga Tikhomirova, PhD, University Professor and researcher with in-depth knowledge in sustainable development and system thinking. She is an accomplished researcher in system approach in management. Olga is an author of more than 65 scientific articles and 10 books on management and entrepreneurship. The scientific fields of interest are the following: entrepreneurship and innovation, sustainable development and system approach, evolution of social systems. From 2000 to current she is an Associate Professor of Management, Department of Production Management and Technology Transfer, Saint-Petersburg National Research University ITMO, Russia. Olga has several state awards in teaching, she is a speaker at some conferences and seminars are dedicated to sustainable development and entreprenuership, works as a business coach. She lectures and motivates student through in-depth lecture and discussion for developing there independent critical thinking and creativity. Olga has developed her own training system based on releasing creative potential and imagination both in business sphere and engineering. 